\title{
COMPOSIÇÃO DO SUBSTRATO, VIGOR E PARÂMETROS FISIOLÓGICOS DE MUDAS DE TIMBAÚVA (Enterolobium contortisiliquum (VELL.) MORONG) ${ }^{1}$
}

Marcelo Vielmo Afonso², Emanuela Garbin Martinazzo ${ }^{3}$, Tiago Zanatta Aumonde ${ }^{4}$ e Francisco Amaral Villela ${ }^{5}$

\begin{abstract}
RESUMO - Este trabalho objetivou avaliar a influência da composição de um substrato organoarenoso sobre a emergência e parâmetros fisiológicos de crescimento de plântulas de timbaúva. As sementes foram submetidas à germinação nas seguintes composições do substrato: $\mathbf{T}_{1}$ ) $100 \%$ areia; $\mathbf{T}_{2}$ ) $75 \%$ areia $+25 \%$ Tecnomax $\left.^{\circledR} ; \mathbf{T}_{3}\right) 50 \%$ areia $\left.+50 \% \operatorname{Tecnomax}^{\circledR}, \mathbf{T}_{4}\right) 25 \%$ areia $+75 \% \operatorname{Tecnomax}^{\circledR} ;$ e $\left.^{\mathbf{T}_{5}}\right) 100 \% \operatorname{Tecnomax}^{\circledR}$. As avaliações foram efetuadas aos 45, 90,135 e 180 dias após a semeadura, aferindo a altura da parte área e o diâmetro do coleto. Aos 180 DAS, determinaram-se a massa da matéria seca de parte aérea, a massa da matéria seca de raízes, a massa da matéria seca total e os teores de clorofila $a, b$ e clorofila total. A emergência e os parâmetros fisiológicos de crescimento foram afetados negativamente pela composição exclusiva de Tecnomax ${ }^{\circledR}$, assim como os valores de clorofila $b$. O substrato comercial associado ao material inerte (areia) proporcionou maior expressão do vigor das sementes, teores de clorofila $b$ e maior crescimento de mudas de timbaúva.
\end{abstract}

Palavras-chave: Teores de clorofila, Biometria e Massa da matéria seca

\section{SUBSTRATE COMPOSITION, VIGOR AND PHYSIOLOGICAL PARAMETERS OF TIMBAÚVA SEEDLINGS (Enterolobium contortisiliquum (VELL.) MORONG)}

\begin{abstract}
The work aimed to evaluate the influence of the composition an organo-sandy substrate on the emergence and physiological parameters of growth in timbaúva seedlings. The seeds were submitted to germination of the substrate in the following compositions: T1) 100\% sand, T2) 75\% sand + 25\% Tecnomax ${ }^{\circledR}$, T3) $50 \%$ sand $+50 \%$ Tecnomax $^{\circledR}$, T4) $25 \%$ sand $+75 \%$ Tecnomax $^{\circledR}$, T5) 100\% Tecnomax ${ }^{\circledR}$. The evaluations were performed at 45; 90; 135 and 180 days after sowing and measured the shoot height and stem diameter. At 180 DAS determined the dry mass of shoot, dry mass of roots, total dry mass and contents of chlorophyll a, chlorophyll $\mathrm{b}$ and chlorophyll total. The emergence and physiological parameters of growth were negatively affected by the unique composition of Tecnomax ${ }^{\circledR}$ as well as the values of chlorophyll $\mathrm{b}$. The commercial substrate associated with inert material (sand) provided higher expression of seed vigor, higher levels of chlorophyll $\mathrm{b}$ and growth of timbaúva seedlings.
\end{abstract}

Keywords: Chlorophyll content, Biometrics and Dry mass.

\footnotetext{
${ }^{1}$ Recebido em 13.03.2012 aceito para publicação em 04.06.2012

${ }^{2}$ Instituto Federal Farroupilha, Campus Panambi, Brasil. E-mail: <marcelovielmo@yahoo.com.br>.

${ }^{3}$ Universidade Federal de Pelotas, Instituto de Biologia, Departamento de Botânica. E-mail: <emartinazzo@gmail.com>.

${ }^{4}$ Universidade Federal de Pelotas, FAEM-Departamento Fitotecnia - Programa de Pós-Graduação em C\&T de Sementes. E-mail:<tiago.aumonde@gmail.com>.

${ }^{5}$ Universidade Federal de Pelotas, Faculdade de Agronomia Eliseu Maciel-FAEM. E-mail: <francisco.villela@ pq.cnpq.br>.
} 


\section{INTRODUÇÃO}

A espécie E. contortisiliquum, conhecida popularmente como timbaúva, é planta de origem brasileira da família Fabaceae, sendo decídua no inverno e heliófita, seletiva higrófita, pioneira e dispersa em várias formações florestais (LORENZI, 2002). Esta espécie é recomendada para reflorestamento de áreas degradadas, de preservação permanente e para plantios mistos, principalmente pelo seu rápido crescimento inicial (ARAUJO; SOBRINHO, 2011).

O setor florestal destacou-se nas últimas décadas por constituir empreendimento rentável a diversos países (BASSO et al., 2011) e devido à procura de espécies arbóreas nativas para utilização em programas de reflorestamento, reconstituição de áreas para preservação vegetal e, ainda, em projetos de arborização urbana que estão se intensificando nos últimos anos (SCALON et al., 2006). Entretanto, diferentemente de plantas de cultivo comercial, há grande lacuna quanto ao conhecimento sobre o potencial germinativo, crescimento de plântulas e plantas de espécies arbóreas nativas e da avaliação de pigmentos envolvidos na captação de energia radiante diante de diferentes composições de substratos.

A aclimatação das plantas a diferentes ambientes depende da capacidade de crescimento e da plasticidade do sistema fotossintético, incluindo alterações nos teores de clorofila e possibilitando maior eficiência na utilização da luminosidade. A clorofila a atua mais efetivamente na fase fotoquímica da fotossíntese, enquanto os demais pigmentos auxiliam na absorção de luz e na transferência da energia radiante para os centros de reação (STREIT et al., 2005). Nesse sentido, a quantificação de pigmentos fotossintéticos conjuntamente com a avaliação do vigor da semente e do crescimento inicial da plântula determinados rotineiramente pelo teste de emergência (PESKE et al., 2006) constituem importantes parâmetros para a estimativa da qualidade das mudas.

O substrato permite o estabelecimento vegetal por garantir o crescimento do sistema radicular e da parte aérea, motivo pelo qual deve apresentar porosidade, capacidade de retenção de água e fornecimento de nutrientes adequados (STURION et al., 2000). Diferentes materiais ou composições de substratos possuem diferentes efeitos sobre a emergência de plântulas, fase crítica do ciclo de desenvolvimento vegetal e que constitui estádio decisivo para o adequado estabelecimento dos indivíduos a campo, devido à elevada vulnerabilidade a estresses ambientais (CASTRO et al., 2004). Tal efeito reflete quantitativamente na produção de biomassa e, assim, sobre o crescimento inicial das plântulas. Dificilmente um único material será capaz de atender todas às exigências da espécie a ser multiplicada e, por essa razão, materiais melhoradores de características físicas são incorporados aos substratos. A escolha dos materiais a serem utilizados para uma formulação adequada do substrato deve considerar a espécie, a disponibilidade e o custo do material (CUNHA et al., 2005). Nesse contexto, o estudo dos parâmetros fisiológicos de emergência, crescimento e dos teores de clorofila em plântulas assume importância na avaliação dos efeitos da composição do substrato quanto ao vigor da semente e à qualidade da muda produzida.

Desse modo, este trabalho objetivou avaliar o efeito da composição de um substrato organoarenoso sobre a emergência e atributos fisiológicos de crescimento de plântulas de timbaúva.

\section{MATERIAL E MÉTODOS}

O trabalho foi realizado em casa de vegetação disposta no sentido norte-sul, localizada no Instituto Regional de Desenvolvimento Rural da Universidade Regional do Noroeste do Estado do Rio Grande do Sul (28 27' 17"S e 535 54' 50"O). Sementes de timbaúva (E. contortisiliquum) foram coletadas no terço médio lateral de matrizes com cerca de $12 \mathrm{~m}$ de altura e localizadas em remanescente vegetal, na região Noroeste do Rio Grande do Sul. As sementes foram submetidas ao processo de secagem natural sobre bandeja com fundo de tela, e a superação de dormência foi realizada pelo método de escarificação mecânica manual, por meio de lixa de madeira no4 por 15 min (ALEXANDRE et al., 2009). Foram dispostas para germinarem em 26/ 03/2011, em tubetes cônicos de polipropileno de cor preta e capacidade de $110 \mathrm{~cm}^{3}$ de substrato, em casa de vegetação. A irrigação foi efetuada por meio do sistema de irrigação por microaspersão, tempo de irrigação de 4 min e frequência de $6 \mathrm{~h}$, totalizando quatro irrigações diárias. A temperatura e radiação solar foram acompanhadas no interior da casa de vegetação, atingindo, respectivamente, as médias de $25 \pm 2{ }^{\circ} \mathrm{C}$ e de $350,12 \mathrm{cal} \mathrm{cm}^{-2} \mathrm{dia}^{-1}$.

Revista Árvore, Viçosa-MG, v.36, n.6, p.1019-1026, 2012 
Os tratamentos foram composições do substrato, onde: $\mathbf{T}_{1}$ ) $100 \%$ areia de textura média $+0 \%$ Tecnomax $^{\circledR}$; $\left.\mathbf{T}_{2}\right) 75 \%$ areia de textura média $+25 \%$ Tecnomax $^{\circledR} ; \mathbf{T}_{3}$ ) $50 \%$ areiade textura média $+50 \%$ Tecnomax $\left.^{\circledR} ; \mathbf{T}_{4}\right) 25 \%$ areiade textura média $+75 \%$ Tecnomax $^{\circledR}$ e $\mathbf{T}_{5}$ ) $0 \%$ areia $+100 \%$ Tecnomax ${ }^{\circledR}$. Todos os tratamentos receberam $8 \mathrm{~g} \mathrm{~L}^{-1}$ de Omoscote ${ }^{\circledR}$ (15-9-12 - período de liberação de cinco a seis meses), conforme recomendação do fabricante.

Avaliou-se a porcentagem de emergência (E) aos 21 dias após a semeadura (DAS), por meio de cinco subamostras de 25 sementes. A altura (A), aferida por meio de régua milimetrada e a partir do colo da plântula ao ápice, e o diâmetro do colo (DC), por meio de paquímetro digital, foram realizados aos 45, 90, 135 e 180 dias após a semeadura (DAS), por meio de quatro amostras de quatro mudas por repetição de tratamento. Aos 180 DAS, as mudas foram separadas em raízes e parte aérea, sendo as raízes lavadas sobre peneira de malha fina com o auxílio de água corrente para a separação do substrato. Para obtenção da massa de matéria seca, o material foi acondicionado em envelopes de papel pardo dispostos na secagem em estufa de circulação de ar forçada a $70{ }^{\circ} \mathrm{C}$, por $72 \mathrm{~h}$.. A massa da matéria seca de parte aérea $\left(\mathrm{MMS}_{\mathrm{PA}}\right)$, de raízes $\left(\mathrm{MMS}_{\mathrm{RAIZ}}\right)$ e total $\left(\mathrm{MMS}_{\mathrm{TOTAL}}\right.$ ) representada pela soma da $\mathrm{MMS}_{\mathrm{PA}}$ e $\mathrm{MMS}_{\mathrm{RAIZ}}$ foram obtidas através de balança analítica e os resultados expressos em miligramas. A relação raiz / parte aérea $\left(\mathrm{MMS}_{\mathrm{RAIZ}} / \mathrm{MMS}_{\mathrm{PA}}\right)$ foi obtida da razão entre $\mathrm{MMS}_{\mathrm{RAIZ}}$ e $\mathrm{MMS}_{\mathrm{PA}}$ e o índice de qualidade de Dickson (IQD) determinadosegundo Dickson et al. (1960), sendo IQD = $\mathrm{MMS}_{\mathrm{TOTAL}} /\left(\mathrm{RAD}+\mathrm{MMS}_{\mathrm{PA}} / \mathrm{MMS}_{\mathrm{RAZ}}\right)$ e RAD refere-se àrazão da altura da parte aérea e o diâmetro do coleto das mudas.

A determinação dos teores de clorofila $a, b$ e total foi efetuada ao final do experimento (180 DAS), utilizando-se quatro amostras de folhas maduras do terço central da parte aérea de quatro mudas provenientes de cada composição do substrato. O material vegetal foi macerado em acetona $80 \%$ e a quantificação dos teores de clorofila $a, b$ e clorofila total $\left(\mathrm{mg} \mathrm{g}^{-1}\right)$, obtida por espectrofotometria de emissão a $645 \mathrm{~nm}$ e $663 \mathrm{~nm}$, conforme metodologia de Arnon (FALQUETO et al., 2009).

O delineamento experimental foi de blocos casualizados, com cinco tratamentos e quatro repetições. Cada unidade experimental foi constituída por cinco amostras de 25 sementes, para avaliação da porcentagem de emergência, e por quatro amostras de quatro mudas, para aferição da altura, diâmetro do colo e massa de matéria seca. As porcentagens de emergência foram transformadas em Arcsen $\sqrt{x / 100}$. Os dados foram submetidos à análise de variância, sendo as médias do substrato comparadas pelo teste de Duncan a 5\% de probabilidade, através do software Winstat, versão 2.0 (MACHADO; CONCEIÇÃO, 2003).

\section{RESULTADOS}

A emergência (E) de plântulas de timbaúva não mostrou diferenças significativas nas composições do substrato dotadas de areia lavada. Entretanto, foi reduzida pela composição exclusiva de Tecnomax ${ }^{\circledR}$ quando comparada com a dos demais tratamentos (Figura 1).

Dados de altura e o diâmetro do colo de mudas de timbaúva são apresentados na Tabela 1. Não houve diferença significativa entre os tratamentos, quanto à altura das plântulasaos 45 DAS. Aos 90 DAS, as composições $\mathbf{T}_{\mathbf{1}}$ e $\mathbf{T}_{\mathbf{2}}$ diferiram significativamente das demais, proporcionando maior altura das plântulas, fato também observado para as mudas em $\mathbf{T}_{1}$ (composição exclusiva de areia)aos 135 e 180 DAS.Aos 180 DAS, menor altura foi observada para as composições $\mathbf{T}_{4} \mathrm{e}$ $\mathbf{T}_{5}\left(\right.$ composição com 75 e $100 \%$ de Tecnomax $\left.^{\circledR}\right)$.Maior diâmetro do colo foi observado nos tratamentos $\mathbf{T}_{\mathbf{1}}$ e $\mathbf{T}_{2}$, de maneira geral, em todas as épocas avaliadas.

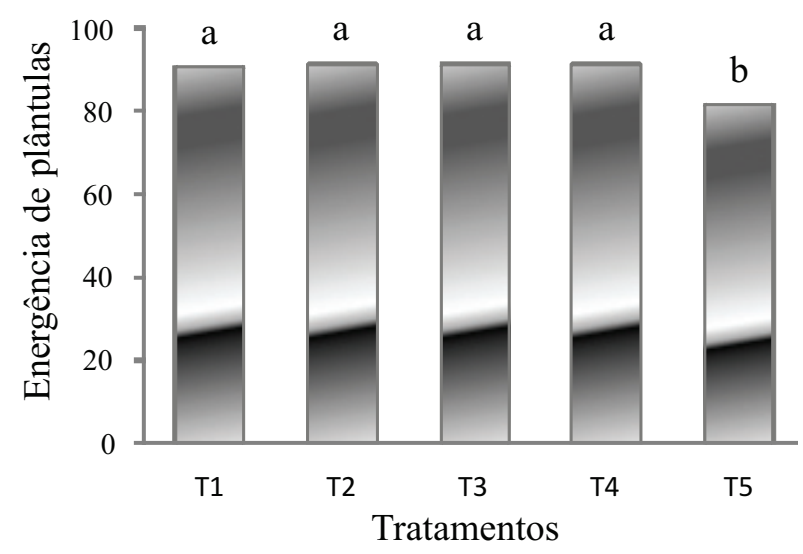

Figura 1 - Porcentagem de emergência de plântulas de timbaúva (Enterolobium contortisiliquum(VELL.) MORONG) em diferentes substratos

Figure 1 - Percentage of seedlingsemergency of timbaúva (Enterolobium contortisiliquum (VELL.) MORONG) on different substrates.

Revista Árvore, Viçosa-MG, v.36, n.6, p.1019-1026, 2012 
Tabela 1 - Altura (A) e diâmetro do colo (D) de mudas de timbaúva(Enterolobium contortisiliquum (VELL.) MORONG)avaliadas até 180 dias após a semeadura, cultivadas em diferentes substratos

Tabela 1 - Height (A) and stem diameter (D) of timbaúva (Enterolobium contortisiliquum (VELL.) MORONG) seedlings evaluated until 180 days after sowing, grown on different substrates

\begin{tabular}{|c|c|c|c|c|c|c|c|c|}
\hline \multirow{3}{*}{ Tratamentos } & \multicolumn{8}{|c|}{ Dias após a semeadura (DAS) } \\
\hline & \multicolumn{2}{|c|}{45} & \multicolumn{2}{|c|}{90} & \multicolumn{2}{|c|}{135} & \multicolumn{2}{|c|}{180} \\
\hline & $\mathrm{A}(\mathrm{cm})$ & $\mathrm{D}(\mathrm{mm})$ & $\mathrm{A}(\mathrm{cm})$ & $\mathrm{D}(\mathrm{mm})$ & $\mathrm{A}(\mathrm{cm})$ & $\mathrm{D}(\mathrm{mm})$ & $\mathrm{A}(\mathrm{cm})$ & $\mathrm{D}(\mathrm{mm})$ \\
\hline $\mathrm{T}_{1}$ & $64,82 \mathrm{a}^{*}$ & 3,05 a & 76,07 a & 4,75 a & $85,10 \mathrm{a}$ & 5,13 a & 117,82 a & 6,07 a \\
\hline $\mathrm{T}_{2}$ & $63,65 \mathrm{a}$ & $2,87 \mathrm{ab}$ & 75,22 a & $4,70 \mathrm{a}$ & $79,17 \mathrm{~b}$ & $4,98 \mathrm{ab}$ & $114,10 \mathrm{a}$ & $5,55 \mathrm{ab}$ \\
\hline $\mathrm{T}_{3}^{2}$ & 60,47 a & $2,57 \mathrm{~b}$ & $69,15 \mathrm{~b}$ & $4,15 \mathrm{~b}$ & $73,37 \mathrm{c}$ & $4,65 \mathrm{bc}$ & $112,07 \mathrm{a}$ & $5,37 \mathrm{~b}$ \\
\hline $\mathrm{T}_{4}$ & 57,67 a & $2,67 \mathrm{~b}$ & $67,80 \mathrm{~b}$ & $4,05 \mathrm{~b}$ & $71,4 \mathrm{c}$ & $4,58 \mathrm{bc}$ & $106,70 \mathrm{ab}$ & $5,25 \mathrm{~b}$ \\
\hline $\mathrm{T}_{5}$ & 58,55 a & $2,65 \mathrm{~b}$ & $64,70 \mathrm{~b}$ & $3,82 \mathrm{~b}$ & $68,07 \mathrm{c}$ & $4,25 \mathrm{c}$ & $95,62 \mathrm{~b}$ & $4,45 \mathrm{c}$ \\
\hline $\mathrm{CV}(\%)$ & 8,0 & 8,4 & 4,8 & 6,0 & 4,7 & 6,0 & 8,5 & 7,0 \\
\hline
\end{tabular}

*Médias seguidas de mesma letra, na coluna, não diferem entre sí pelo teste de Duncan a 5\% de probabilidade.

Aos 180 DAS, amassa da matéria seca de parte aérea e total na composição exclusiva de Tecnomax ${ }^{\circledR}$ foram inferiores as demais composições (Tabela 2).A massa seca de raiz foi maior em mudas crescidas na composição $\mathbf{T}_{2}$ diferindo dos tratamentos $\mathbf{T}_{4}(50 \%$ areia) e $\mathbf{T}_{5}$. A massa seca da parte aérea, a massa seca da raiz e a massa seca total das mudas cultivadas em areia foram $81 \%, 88 \%$ e $89 \%$ superiores, respectivamente as das mudas cultivadas em substrato Tecnomax ${ }^{\circledR}$.

A relação $\mathrm{MS}_{\mathrm{RAIZ}}$ / PA, não mostrou diferença entre as composições. O índice de qualidade de Dickson (IQD) em todas as composições dotadas de areia não diferiu entre si, enquanto a composição exclusiva de Tecnomax ${ }^{\circledR}$ atingiu menor índice (Tabela 2). O IQD, segundo Fonseca et al. (2002), é um eficiente indicador de qualidade de mudas, pois considera a robustez e o equilíbrio da distribuição da biomassa entre órgãos da planta, ponderando resultados de vários parâmetros relevantes empregados na avaliação da qualidade.

O teor de clorofila $a$ e a relação clorofila $a / b$ não apresentaram diferenças significativas(Tabela 3). Em relação aos teores de clorofila $b$, menores valores foram encontrados para as mudas crescidas em composição exclusiva de Tecnomax ${ }^{\circledR}\left(\mathbf{T}_{5}\right)$, que também apresentaram menor teor de clorofila total comparativamente a mudas de $\mathbf{T}_{\mathbf{2}}$.

\section{DISCUSSÃO}

Provavelmente, a menor emergência na composição exclusiva de Tecnomax ${ }^{\circledR}$ tenha sido função da menor porosidade do substrato na ausência de areia na composição, indicando redução na expressão do vigor da semente pelo tratamento $\mathrm{T}^{5}$. Portanto, segundo Peske et al. (2006), é possível que a emergência tenha sido afetada pela influência do referido substrato sobre a ativação do sistema metabólico hidrolítico, resultando em menor conversão de amido em açúcares prontamente absorvíveis e destinados à retomada do crescimento do embrião. Dados referentes ao tipo de substrato são fundamentais no processo germinativo e estabelecimento da muda. Em estudo realizado com sementes de seringueira, observou-se que tanto o substrato areia quanto o vermiculita foram adequados à emergência de plântulas (GARCIA; VIEIRA, 1994).

Embora a areia possua menor capacidade de retenção de umidade e nutriente em relação a substratos de composição orgânica, ela apresenta vantagem em relação à quantidade de luz que permite chegar à semente, fator de grande importância, pois influencia diretamente na germinação das sementes e na emergência das plântulas (FIGLIOLIA et al., 1993). A areia, por suas características, confere condições adequadas de substrato para germinação, como porosidade e esterilidade. A porosidade permite o movimento de água e ar no substrato, favorecendo a germinação, a qual necessita apenas de hidratação e aeração da semente para que se procedam às reações enzimáticas (NOGUEIRA et al., 2003) e alterações hormonais que induzam à formação do caulículo e da radícula.

Embora a areia seja isenta de matéria orgânica, a maior altura de mudas, observada nas composições $\mathbf{T}_{1}$ e $\mathbf{T}_{2}$ aos 90 dias e para $\mathrm{T}_{1}$ aos 135 dias pode ser atribuída à utilização de Osmocote ${ }^{\circledR}$ como fonte de

Revista Árvore, Viçosa-MG, v.36, n.6, p.1019-1026, 2012 
Tabela 2 - Massa da matéria seca da parte aérea $\left(\mathrm{MMS}_{\mathrm{PA}}\right)$, massa da matéria seca da raiz $\left(\mathrm{MMS}_{\mathrm{RAIZ}}\right)$, massa da matéria seca total $\left(\mathrm{MMS}_{\mathrm{TOTAL}}\right)$, relação massa seca da raiz e parte aérea $\left(\mathrm{MMS}_{\mathrm{RAIZ}} / \mathrm{MMS}_{\mathrm{PA}}\right)$ e índice de qualidade de Dickson (IQD) de mudas de timbaúva(Enterolobium contortisiliquum (VELL.) MORONG) aos 180 dias após semeadura, cultivadas em diferentes substratos

Tabela 2 - Shoot dry mass $\left(M M S_{P A}\right)$, root dry mass $\left(M M S_{R O O T}\right)$, total dry matter $\left(M M S_{\text {TOTAL }}\right)$, relationship dry mass of root and shoot $\left(M M S_{R O O I} / M M S_{P A}\right)$ and Dickson quality index (IQD) of timbaúva (Enterolobium contortisiliquum (VELL.) MORONG) seedlings at 180 days after sowing, grown on different substrates

\begin{tabular}{cccccc}
\hline Tratamentos & $\mathrm{MMS}_{\mathrm{PA}}(\mathrm{mg})$ & $\mathrm{MMS}_{\mathrm{RAIZ}}(\mathrm{mg})$ & $\mathrm{MMS}_{\text {TOTAL }}(\mathrm{mg})$ & $\mathrm{MMS}_{\mathrm{RAIZ}} / \mathrm{MMS}_{\mathrm{PA}}$ & $\mathrm{IQD}$ \\
\hline $\mathrm{T}_{1}$ & $1829,0 \mathrm{a}^{*}$ & $1805,0 \mathrm{ab}$ & $3634,0 \mathrm{a}$ & $0,980 \mathrm{a}$ & $0,175 \mathrm{a}$ \\
$\mathrm{T}_{2}$ & $1834,0 \mathrm{a}$ & $2002,0 \mathrm{a}$ & $3836,0 \mathrm{a}$ & $1,091 \mathrm{a}$ & $0,178 \mathrm{a}$ \\
$\mathrm{T}_{3}$ & $1697,0 \mathrm{a}$ & $1843,0 \mathrm{ab}$ & $3540,0 \mathrm{a}$ & $1,103 \mathrm{a}$ & $0,163 \mathrm{a}$ \\
$\mathrm{T}_{4}$ & $1544,0 \mathrm{a}$ & $1593,0 \mathrm{~b}$ & $3137,0 \mathrm{a}$ & $1,057 \mathrm{a}$ & $0,147 \mathrm{a}$ \\
$\mathrm{T}_{5}$ & $1012,0 \mathrm{~b}$ & $913,0 \mathrm{c}$ & $1925,0 \mathrm{~b}$ & $0,972 \mathrm{a}$ & $0,084 \mathrm{~b}$ \\
\hline $\mathrm{CV}(\%)$ & 19,0 & 14,0 & 14,0 & 18,0 & 14,0 \\
\hline
\end{tabular}

*Médias seguidas de mesma letra, na coluna, não diferem entre sí pelo teste de Duncan a 5\% de probabilidade

Tabela 3 - Valores médios da clorofila $a(\mathrm{Chl} a), b(\mathrm{Chl} b)$, total (Chltotal) e relação entre clorofila a e b (Chl $a / b)$ em mudas de timbaúva (Enterolobium contortisiliquum (VELL.) MORONG)aos 180 dias após semeadura, cultivadas em diferentes substratos. MF refere-se à matéria fresca.

Tabela3 - Mean values of chlorophyll a (Chla), b (Chlb), total (Chltotal) and the relationship between chlorophyll a and $b(C h l a / b)$ in timbaúva (Enterolobium contortisiliquum (VELL.) MORONG) seedlings to 180 days aftersowing, grown on different substrates. MF refers to the fresh weight

\begin{tabular}{ccccc}
\hline Tratamentos & Chl $a\left(\mathrm{mg} \mathrm{g}^{-1} \mathrm{MF}\right)$ & $\mathrm{Chl} b\left(\mathrm{mg} \mathrm{g}^{-1} \mathrm{MF}\right)$ & $\mathrm{Chl}$ total $\left(\mathrm{mg} \mathrm{g}^{-1} \mathrm{MF}\right)$ & $\mathrm{Chl} a / b$ \\
\hline $\mathrm{T}_{1}$ & $1,575 \mathrm{a}^{*}$ & $1,148 \mathrm{a}$ & $2,722 \mathrm{ab}$ & $1,427 \mathrm{a}$ \\
$\mathrm{T}_{2}$ & $1,537 \mathrm{a}$ & $1,343 \mathrm{a}$ & $2,879 \mathrm{a}$ & $1,163 \mathrm{a}$ \\
$\mathrm{T}_{3}$ & $1,554 \mathrm{a}$ & $1,110 \mathrm{a}$ & $2,663 \mathrm{ab}$ & $1,415 \mathrm{a}$ \\
$\mathrm{T}_{4}$ & $1,581 \mathrm{a}$ & $1,148 \mathrm{a}$ & $2,728 \mathrm{ab}$ & $1,390 \mathrm{a}$ \\
$\mathrm{T}_{5}$ & $1,517 \mathrm{a}$ & $1,004 \mathrm{~b}$ & $2,520 \mathrm{~b}$ & $1,526 \mathrm{a}$ \\
\hline $\mathrm{CV}(\%)$ & 4,0 & 7,0 & 6,0 & 10,0 \\
\hline
\end{tabular}

*Médias seguidas de mesma letra, na coluna, não diferem entre sí pelo teste de Duncan a 5\% de probabilidade.

nutrientes, o que permite a disponibilidade contínua de nutrientes para as plântulas, minimizando a probabilidade de ocorrerem deficiências nutricionais durante o período de formação das mudas. Tal ocorrência foi evidenciada em mudas de maracujazeiro-amarelo cultivadas em substratos com composição de resíduos agroindustriais, que apresentaram melhor estado nutricional em virtude da utilização de Osmocote ${ }^{\circledR}$ (SERRANO et al., 2006).

Para espécies nativas, mudas de qualidade devem apresentar diâmetro do colo entre 5 e $10 \mathrm{~mm}$ (GONÇALVES et al., 2000). Verificou-se, portanto, que aos 135 dias as mudas de timbaúva cultivadas em substrato contendo 100 e $75 \%$ de areia já apresentavam essa característica. O maior diâmetro do colo sugere maior alocação de fotoassimilados na parte aérea, podendo ser aspecto considerado para indicar a capacidade de sobrevivência de mudas em condições de campo e auxiliar na definição das doses de fertilizantes a serem utilizadas na produção das mudas (SCALON et al., 2001).

Em relação à massa de matéria seca da parte aérea, esta é considerada indicativo da capacidade de resistência da planta às condições adversas de ambiente (MORGADO et al., 2000). Maior massa de matéria seca de parte aérea pode constituir reservatório temporário de assimilados, pois estes compostos, ao serem alocados no caule, podem ser translocados e alocados para a formação de folhas, permitindo a formação de maior área de captação de energia radiante e contribuindo para a elevação da massa 
de matéria seca total (MARENCO; LOPOES, 2005). Raízes com maior massa de matéria seca possuem tendência a apresentar maior número de ápices radiculares, região da raiz que mais possui eficiência na absorção e transporte de água e nutrientes e, principalmente, na produção de fitormônios (REIS et al., 1989).

Caldeira et al. (2008), relatam que a relação $\mathrm{MS}_{\mathrm{RAIZ}}$ /PAdeve ser 1:2, fato não observado em mudas de timbaúva crescidas nas diferentes composições de substrato testadas. Entretanto, deve ficar claro que existem divergências quanto aos valores dessa relação, pois, ao analisarem a massa de matéria seca total e a relação entre massa de matéria seca de raiz e parte aérea, Saidelles et al. (2009) afirmaram que a parte aérea deve contribuir de forma a ser similar à raiz, em razão de possíveis limitações quanto à absorção de água para a parte aérea.

Estabelecendo como padrão o valor mínimo de IQD em 0,2 nas mudas de coníferas produzidas em recipientes de 50 ou $60 \mathrm{~mL}$, Hunt (1990) observou que as mudas atingiram o referido valor a partir dos 120 dias após a emergência. Embora, neste estudo, os tratamentos compostos por areia tenham revelado melhores resultados, é possível observar que aos 180 DAS mudas de timbaúva não atingiram o IQD de 0,20. Nesse sentido, Marques et al. (2009), ao avaliarem o crescimento de mudas de jacaré em diferentes tipos de solos e sem adubação nitrogenada, observaram que aos 120 DAS as mudas apresentaram o IQD de 0,27. Enquanto Nóbrega et al. (2008), avaliando o desempenho de duas mudas de espécies florestais cultivadas em diferentes composições de substrato e contendo lixo urbano, verificaram que, na ausência do lixo e aos 150 DAS, mudas de angico atingiram o IQD de 0,6 e mudas de sesbania, de 1,7. Nesse sentido, cabe salientar que o IQD é variável entre genótipos; logo, o IQD ótimo para determinado genótipo pode não ser necessariamente ideal para outros.

Um dos fatores mais importantes para o crescimento e adaptação das plantas aos diferentes ambientes é o conteúdo de clorofila (RÊGO; POSSAMAI, 2008). Plantas dotadas de elevados teores de clorofila podem atingir taxas fotossintéticas mais altas, devido ao potencial de captação de "quanta" na unidade de tempo (MARENCO; LOPES, 2005). Além disso, Reid et al. (1991) afirmaram que o aumento da capacidade de absorção de luz pode ser fator decisivo para a maior formação de assimilados, refletindo em mudas de qualidade superior com melhor desempenho em campo. Aclorofilab, pigmento que capta radiação luminosa de comprimento de onda diferente da clorofila $a$, transfere a energia para a clorofila $a$, que efetivamente atua nas reações fotoquímicas da fotossíntese (SCALON et al., 2003). As clorofilas $a$ e $b$ apresentam-se na natureza em plantas heliófitas como a timbaúva, na proporção de 3:1 (STREIT et al., 2005). Entretanto, em plantas umbrófitas essa relação pode ser diferente, sendo importante salientar que os teores de clorofila apresentam variação entre genótipos e sofrem alterações de acordo com as condições edafoclimáticas em que ocorrem o crescimento e desenvolvimento da planta (MARENCO; LOPES, 2005). Nesse contexto, mudas crescidas nas composições dotadas de areia apresentaram maiores teores de clorofila b e similares teores de clorofila a relativamente àquelas crescidas em subtrato composto exclusivamente por Tecnomax $^{\circledR}$. Isto, provavelmente favoreceu omaior crescimento, pelamaior eficiência na captação de energia radiante e sua conversãoem energia química. Desse modo, pode ter favorecido a síntese e alocação de assimilados, bem como, a obtenção de mudas com padrão superior. Entretanto,é interessante salientar que, embora os tratamentos $\mathbf{T}_{1}, \mathbf{T}_{3}, \mathbf{T}_{4}$ e $\mathbf{T}_{5}$ não tenham diferido quanto à clorofila total, verifica-se em valores absolutos, a superioridade dos tratamentos $\mathbf{T}_{\mathbf{1}}, \mathbf{T}_{\mathbf{3}}$ e $\mathbf{T}_{\mathbf{4}}$ em relação a $\mathbf{T}_{5}$, variável de $5,7 \%\left(\mathbf{T}_{3}\right)$ a $10 \%\left(\mathbf{T}_{1}\right)$.

\section{CONCLUSÕES}

O uso isolado de substrato comercial possibilita menor emergência de plântulas e afeta negativamente as características de crescimento e os teores de clorofila. O substrato comercial associado ao material inerte areia proporciona maior expressão do vigor de sementes, teor superior de clorofila $b$ e total e maior crescimento de mudas, evidenciando ser mais adequado para a formação de mudas de timbaúva.

\section{REFERÊNCIAS}

ALEXANDRE, R.S. et al. Tratamentos físicos e químicos na superação de dormência em sementes de E. contortisiliquum (Vell.) Morong. Revista Brasileira de Ciências Agrárias, v.4, n.2, p.156-159, 2009.

ARAUJO, A.; PAIVA SOBRINHO, S. Germinação e produção de mudas de tamboril ( $E$. contortisiliquum (Vell.) Morong) em diferentes substratos. Revista Árvore, v.35, n.3, p.581588,2011 . 
BASSO, V. M. et al. Influência da certificação florestal no cumprimento da legislação ambiental e trabalhista na região amazônica. Acta

Amazonica, v.41, n.1, p.69-76, 2011.

CALDEIRA, M.V.W. et al. Composto orgânico na produção de mudas de aroeira-vermelha.

Scientia Agraria, v.9, n.1, p.27-33, 2008.

CASTRO, R.D.; BRADFORD, K.J.; HILHORST,

H.W.M. Desenvolvimento de sementes e conteúdo de água. In: FERREIRA, A.G.; BORGHETTI, F. (Orgs.). Germinação: do básico ao aplicado.Porto Alegre: Artmed, 2004. p.149-162.

CUNHA, A.O. et al. Efeitos de substratos e das dimensões dos recipientes na qualidade das mudas de Tabebuia impetiginosa (Mart. Ex D.C.) Standl. Revista Árvore, v.29, n.4, p.507-516, 2005.

DICKSON, A. et al. Quality appraisal of white spruce and white pine seedling stock in nurseries. Forest Chronicle, v.36, n.1, p.10-13, 1960.

FALQUETO, A.R.et al.Physiological analysis of leaf senescence of two rice cultivars with different yield potential. Pesquisa

Agropecuária Brasileira, v.44, n.7, p.695$700,2009$.

FIGLIOLIA, M.B.; OLIVEIRA, E.C.; PIÑARODRIGUES, F.C.M. Análise de sementes. In: AGUIAR, I.B.; PIÑA-RODRIGUES, F.C.M.; FIGLIOLIA, M.B.Sementes florestais tropicais. Brasília: Abrates, 1993. p.137-174.

FONSECA, E.P. et al. Padrão de qualidade de mudas de Trema micrantha (L.) Blume, produzidas sob diferentes períodos de sombreamento.

Revista Árvore, v.26, n.4, p.515-523, 2002.

GARCIA, A.; VIEIRA, R.D. Germinação, armazenamento e tratamento fungicida de sementes de seringueira (Hevea brasiliensis Muell. Arg.). Revista Brasileira de Sementes, v.16, n.2, p.128-133, 1994.

GONÇALVES, J.L.M. et al. Produção de mudas de espécies nativas: substrato, nutrição, sombreamento e fertilização. In: GONÇALVES, J.L.M.; BENEDETTI, V. Nutrição e fertilização florestal. Piracicaba: IPEF, 2000. p.310-350.

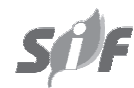

HUNT, G.A. Effect of styroblock design and cooper treatment on morphology of conifer seedlings. In: TARGET SEEDLINGS SYMPOSIUM, MEETING OF THE WESTERN FOREST NURSERY ASSOCIATIONS, Roseburg, 1990.

Proceedings...Fort Collins: United States Departament of Agriculture, Forest Service, 1990. p.218-222. (RM-GTR-200).

LORENZI, H. Árvores brasileiras: manual de identificação e cultivo de plantas arbóreas nativas do Brasil. Nova Odessa: Plantarum, 2002. 368p.

MACHADO, A.A.; CONCEIÇÃO, A.R. Sistema de análise estatística para windows. WinStat. Versão 2.0. Pelotas: Universidade Federal de Pelotas, 2003.

MARENCO, R.A.; LOPES, N.F. Fisiologia vegetal: fotossíntese, respiração, relações hídricas e nutrição mineral.2.ed.Viçosa, MG: Universidade Federal Viçosa, 2005. 451p.

MARQUES, L.S. et al. Crescimento de mudas de jacaré (Piptadenia gonoacantha J.F. Macbr.) em diferentes tipos de solos e fontes e doses denitrogênio. Revista Árvore, v.33, n.1, p.8192, 2009.

MORGADO, I.F. et al. Resíduos agroindustriais prensados como substrato para a produção de mudas de cana-de-açúcar. Scientia Agricola, v.57, n.4, p.709-712, 2000.

NÓBREGA, R. S. A. et al. Parâmetros morfológicos de mudas de Sesbania virgata (Caz.) Pers e de Anadenanthera peregrina (L.) cultivadas em substratofertilizado com composto de lixo urbano. Revista Árvore, v.32, n.3, p.597-607, 2008.

NOGUEIRA, R.J.M.C.; ALBUQUERQUE, M.B.; SILVA JUNIOR, J.F. Efeito do substrato na emergência, crescimento e comportamento estomático em plântulas de mangabeira.Revista Brasileira de Fruticultura, v. 25, n.1, p.15$18,2003$.

PESKE, S.T.; LUCA FILHO, O.A.; BARROS, A.C.S.A. Sementes: fundamentos científicos e tecnológicos.2.ed. Pelotas: Universidade Federal de Pelotas, 2006. p.470.

Revista Árvore, Viçosa-MG, v.36, n.6, p.1019-1026, 2012 
REID, D.M.; BEALL, E.D.; PHARIS, R.P.

Environmental cues in plant growth and development. In: STEWARD, F. C. (Ed). Plant physiology. San Diego: Academic Press, 1991. p.65-181. (Growthand Development, 10).

RÊGO, G.M.; POSSAMAI, E. Avaliação dos teores de clorofila no crescimento de mudas de jequitibá-rosa

(Carinianalegalis).,

Colombo:Embrapa,2008.(Comunicado Técnico, 128)

REIS, G.G.; REIS, M.G.F.; MAESTRI, M. Crescimento de Eucalyptus camaldulensis, E. grandis e E. cloeziana sob diferentes níveis de restrição radicular.Revista Árvore, v.13, n.1, p.1-18, 1989.

SAIDELLES, F.L.F. et al. Casca de arroz carbonizada como substrato para produção de mudas de tamboril-da-mata e garapeira. Semina: Ciências Agrárias, v.30, n.1, p.1173-1186, 2009.

SCALON, S.P.Q. et al. Germinação e crescimento inicial da muda de orelha-de-macaco (Enterolobium contortisiliqunn (Vell.) Morong): efeito de tratamentos químicos e luminosidade. Revista Árvore, v.30, n.4, p.529-536, 2006.
SCALON,S.P.Q. et al. Crescimento inicial de mudas de Bombacopsis glabra (Pasq.) A. Robyns sob condição de sombreamento.Revista Árvore, v.27, n.6, 753-758, 2003.

SCALON, S.P.Q. Germinação e crescimento de mudas de pitangueira (Eugenia uniflora L.) sob condições de sombreamento. Revista Brasileira de Fruticultura, v.23, n.3, p.652-655. 2001.

SERRANO, L.A.L. et al. Utilização de substrato composto por resíduos da agroindústria canavieira para produção de mudas de maracujazeiro-amarelo. Revista Brasileira de Fruticultura, v.28, n.3, p.487-491, 2006.

\section{STREIT, M.N.et al.As clorofilas. Ciência} Rural, v.35, n.3, p.748-755, 2005.

STURION, J.A.; ANTUNES, J.B.M. Produção de mudas de espécies florestais. In: GALV ÃO, A.P.M. Reflorestamento de propriedades rurais para fins produtivos e ambientais. Brasília: Embrapa, 2000. p.125-150. 